Eastern Illinois University

The Keep

Student Honors Theses

Economics

2017

\title{
On The Empirics of User-Fees, Maternal Health- Seeking Behavior and Child Survival in Ghana
}

Ahmed Salim Nuhu

Eastern Illinois University

Follow this and additional works at: http://thekeep.eiu.edu/economics_students

Part of the Economics Commons

\section{Recommended Citation}

Nuhu, Ahmed Salim, "On The Empirics of User-Fees, Maternal Health-Seeking Behavior and Child Survival in Ghana" (2017). Student Honors Theses. 1.

http://thekeep.eiu.edu/economics_students/1

This Article is brought to you for free and open access by the Economics at The Keep. It has been accepted for inclusion in Student Honors Theses by an authorized administrator of The Keep. For more information, please contact tabruns@eiu.edu. 


\title{
On The Empirics of User-Fees, Maternal Health-Seeking Behavior and Child Survival in Ghana
}

\author{
Ahmed Salim Nuhu ${ }^{1}$
}

\begin{abstract}
This paper seeks to answer a simple question; what happens to maternal health seeking-behavior when user-fees are eliminated? We analyze this question empirically by investigating the effects of the free maternal health care (Health Insurance) policy instituted by the government of Ghana, on a variety of health utilization measures and child survival outcomes. Using robust linear and binomial logistic estimation techniques, we find evidence from over 4,000 households, that eliminating user-fees significantly increases the utilization of skilled delivery assistance whilst simultaneously reducing the number of deliveries assisted by unskilled birth attendants. Utilization of antenatal and postnatal care experience similar effects with user-fee elimination. Even though intention to use contraceptives increases with enrollment in the programme, education is found to be more important than health insurance in influencing the number of children a woman desires to have. This paper provides empirical support for the growing calls for removal of user-fees, in order to expand healthcare access and promote inclusion.
\end{abstract}

\section{Introduction}

More than half of women in the developing world still lack access to skilled attendant services at birth delivery; a proxy for measuring maternal healthcare progress. Indeed it is estimated that 239 out of every 100,000 live births result in maternal mortality. To reduce maternal mortality, women will need access to quality maternal healthcare which in turn requires effective policy interventions (WHO, 2015). Consequently, enhancing access to maternal healthcare and ensuring universal health coverage remains high on the agenda of both the United Nations' Millennium and Sustainable Development Goals (MSDGs) and individual nations.

\footnotetext{
${ }^{1}$ Department of Economics ahmedsalimnuhu@gmail.com ; anuhu@eiu.edu
} 
In the developing world, the political momentum towards the attainment of the MSDGs, coupled with the perceived ineffectiveness of current health care financing methods in ensuring both equity in healthcare and sustainable revenue mobilization has led many countries to explore alternative approaches to healthcare financing (Mclntyre, Thiede, Dahlgren, \& Whitehead, 2006; Witter, 2005). Generally however, the recognition that health-service user fees (hence user fees) represents a significant demand-side barrier to access has led many countries to institute fee exemptions for particular groups like pregnant women, institute public health insurance schemes or to completely eliminate user fees (Ensor \& Cooper, 2004; James et al., 2006). The gravitation of countries towards this policy direction has revitalized the academic discourse regarding health user-fees and its implications for health outcomes. In a survey of the literature, we find two divergent opinions.

The strand of the literature that advocates the elimination of user-fees is built on both macro and micro-level evidence that suggests that it helps to foster equity and inclusion in healthcare access, thereby, protecting vulnerable groups like pregnant women and children developing countries, from preventable mortality (Fabricant, Kamara, \& Mills, 1999; Haddad \& Fournier, 1995; Jacobs \& Price, 2004; Uzochukwu, Onwujekwe, \& Eriksson, 2004).

Conversely, this view has been challenged by a section of the empirical health economics literature which argues that imposing user fees provides a sustainable channel for revenue mobilization for quality healthcare financing (Diop, Yazbeck, \& Bitran, 1995). In Benin for example, Soucat et al. (1997) argued that following the Bamako Initiative ${ }^{2}$, service utilization for both preventive and curative care increased, as a result of improved quality of care and enhanced drug availability. In Cambodia, both Akashi, Yamada, Huot, Kanal, and Sugimoto (2004) and Barber, Bonnet, and Bekedam (2004) found that the conversion of previously individualized userfee payments into standardized payments helped increase patronage as client satisfaction rose

\footnotetext{
${ }^{2}$ The Bamako Initiative, sponsored by UNICEF and WHO and adopted by African ministers of health in 1987, was based on the realization that, despite accepting in principle the core tenets of comprehensive primary health care, by the late 1980s many countries - especially in sub-Saharan Africa - were burdened by a lack of resources. Consequently, many countries in Africa, resorted to instituting user fees with exemptions and waivers for certain groups (UNICEF, 1999)
} 
through enhanced staff motivation and improvement in hospital infrastructure. Ellis (1987) and Audibert and Mathonnat (2000) found similar evidence from Niger and Mauritania respectively. These views are also founded on the argument that weak institutions, and the inability of policy makers in developing countries to clearly define the criteria for granting fee waivers and exemptions, and in defining the optimal levels of medical coverage have often resulted inefficient outcomes (Bitrán \& Giedion, 2002).In Burundi for example, Bate and Witter (2003) found that user fee exemption policies were rendered ineffective by the inability of authorities to clearly define the class of beneficiaries, resulting in sub-optimal enrolment levels. Russell and Abdella (2002) presents similar evidence from Ethiopia, where the limited definition of the width of beneficiaries and the depth of medical coverage, severely undermined the effectiveness of the exemption policy.

But extant evidence suggests that the outcomes vary with country and the program under study (James et al., 2006). As such, using generalized global estimates may be inappropriate for domestic planning (Borghi et al., 2006). Therefore, designing optimal health intervention policies require evidence based on country-level and program-specific evaluations. Towards this goal, this paper seeks to contribute to our current understanding of the long-run impact of health user fee elimination on maternal and child health outcomes in Ghana.

In this paper we investigate the long-run implications of the Ghana Free Maternal Health Care Policy (also FMHCP) for a range of maternal and child health outcomes using a nationallyrepresentative micro data. Specifically, we employ an array of linear, binomial logistic estimation techniques to examine the impact of the FMHCP on the choice of delivery assistance methods at birth, family planning and child survival probabilities, for the first time in the empirical health economics literature.

The Free Maternal Health Care Policy introduced by the government of Ghana as part of efforts to enhance access to maternal healthcare provides health insurance to pregnant women, by exempting them from paying insurance premium or renewal fees upon expiry. The insurance grants them access to comprehensive maternity care; antenatal care, delivery services, postnatal and neonatal care as well as all other existing services provided under the National Health 
Insurance Scheme (Dixon, Tenkorang, Luginaah, Kuuire, \& Boateng, 2014; Dzakpasu et al., 2012)). The program which began in 2003 , has since undergone a number of significant reforms, which affected its funding, effectiveness and sustainability. A more detailed overview of the FMHCP is given in section 2 .

But specifically, the early reforms of 2007, posed significant challenges in the areas of management and funding which precipitated labour unrest in the health sector as unpaid compensations coupled with increasing health staff workload caused wide labour dissatisfaction. This raised doubts on the effectiveness of the policy in attaining its intended objectives. For example, it is argued based on evidence from Demographic and Health Surveys that the steady gains made from 1993-2003 in the proportion of deliveries with skilled attendants (Witter, Arhinful, Kusi, \& Zakariah-Akoto, 2007), experienced negative growth between 2005-2007 due to the challenges outlined earlier (Witter, Adjei, Armar-Klemesu, \& Graham, 2009). However, seven years after the reforms, and more than a decade since its inception, there is yet to be a detailed econometric analysis of its implications on maternal and child outcomes.

Accordingly, this paper seeks to fill this gap by contributing to our understanding of the long-run impact of the free maternal healthcare initiative in Ghana using robust econometric estimation techniques and data from the 2014 Demographic and Health Surveys data. Whilst this paper generally contributes to a growing body of literature that examines the implications of healthuser fees abolition, it is unique in the range of outcome variables along which the impact of the program is examined. Again we recognize that the existence of rural-urban and regional disparities in health resource endowments and non-facility costs may influence the degree to which our main regressor impacts our outcome variables, for different individuals. Consequently, we control for rural-urban as well as regional fixed effects in all our estimated models.

In the section that follows, we review relevant literature. Section 3 provides a description of the data used and methodologies used whilst section 4 and 4 presents the discussion of our findings as well as vital policy recommendations.

\section{Literature Review}

a. On the Empirics of User-Fee and Health Outcomes 
In the wake of the adoption of the Bamako Initiative in 1987, many African countries instituted user-fees as part of strategies designed to raise resources to finance the supply of essential drugs and other critical healthcare expenditure in the region. This sparked the emergence of a large body of both theoretical and empirical literature on the implications of user fee, for equity, service utilization and the quality of care. This section provides a brief insight into the evidence from the existing literature. For a more detailed review of the literature please see, "To Retain or To Remove User Fees: Reflections on the Current Debate" (James et al., 2006).

In the Democratic Republic of Congo, Haddad and Fournier (1995) found that user fee implementations significantly reduced service utilization even as quality of service improved. Nyonator and Kutzin (1999) notes that the existing user-fee systems in 1999, reduced utilization amongst low-income populations, perpetuating a high level of sustainable inequity in medical care access in Ghana. Conversely, Uzochukwu et al. (2004), Audibert and Mathonnat (2000), Diop et al. (1995), Mariko (2003) and Chawla and Ellis (2000) argue based on evidence from other African countries, that the institution of user-fees had little or no negative impact on utilization, as quality remained an important determinant of healthcare demand. On the other side of the debate, are studies that have found that the elimination of user fees generally helps to increase utilization, promote equity and inclusion and improve health outcomes (Deininger \& Mpuga, 2004) although not all of them have been efficient (Bitrán \& Giedion, 2002).

As part of efforts to reduce maternal mortality and achieve the MDGs, Ghana in 2003, implemented the Free Maternal Healthcare Policy which initially exempted pregnant women from delivery-related fees. Later in 2007 the exemption regime was replaced with health free comprehensive access to obstetric care under the National Health Insurance Scheme (Hera and Partners, 2013). Although there has been several regional and hospital-level evaluations of the program since its inception, (Bosu, Bell, Armar-Klemesu, \& Tornui, 2007; Witter et al., 2007; Witter, Garshong, \& Ridde, 2013), the evaluations have been largely descriptive and without any econometric foundation. 
This paper attempts to fill this gap by providing an econometric analysis of the long-run implications of FMHCP for maternal healthcare and child survival outcomes in Ghana. In the next section we provide a brief background of healthcare financing and the FMHCP in Ghana.

\section{b. Healthcare Financing and the Free Maternal Healthcare Policy in Ghana}

The overthrow of Ghana's first government in 1966, marked the end of the fully publicly financed healthcare system and simultaneously marked the beginning of out-of-pocket payments by patients, popularly known as the "cash and carry". In 2003, following a pilot exercise in four regions, an as part of efforts towards the attainment of the Millennium Development Goals, a nationwide fee exemption policy was introduced to cover both public and private-facility based obstetric deliveries. Though the program was funded with a debt relief fund under the Highly Indebted Poor Countries (HIPC) initiative, the funding became inadequate as the utilization of the service increased (Witter et al., 2007) (Ministry of Health, 2004). To address these challenges and provide a more universal health coverage, the fee exemption policy was phased out in 2007 and replaced with the National Health Insurance Scheme (NHIS) in 2008. The scheme provided pregnant women the right to a free and instant enrolment on the NHIS which in turn offered them access to the existing medical benefits covered under the scheme, as well as comprehensive obstetrical care and a three-month period of free neonatal health care (Hera, 2013).

On the down side, the program does not cover non-facility costs such as ambulance services and costs of conveying women in labour to delivery facilities. Whilst this may not be a significant challenge in urban and well developed areas, the absence of free ambulance services, coupled with long distance to delivery facilities in rural areas presents a significant challenge to reducing maternal mortality in rural areas (Witter et al., 2007). Additionally, the visible disparities in the relative endowments of health facilities between urban and rural areas could also explain why pregnant women in rural areas use traditional birth attendants instead of delivering at an authorized facility (Ghana Health Service, 2015). For example, according to the data used for this study, the proportion of deliveries with traditional birth attendants stood at about $26 \%$ among women in rural areas, as against $0.07 \%$ among women in urban areas. 
Conversely, $76 \%$ of the women surveyed in urban areas reported having delivered with a nurse or midwife, as against $50 \%$ of women in rural areas.

Evidently, the disparities in ease of access has the potential to result in unequal impact of the policy on women in different regions and areas. To empirically understand these interactions and how they influence maternal and child health outcomes, all the models estimated in this paper control for rural residency as well as regional fixed-effects. In the section that follows, we give a more detailed overview and description of the data and methodology employed in this paper

\section{Data}

a. Survey Design

This paper uses household survey data from the 2014 Ghana Demographic and Health Survey (GDHS) administered by the United States Agency for International Development (USAID). The survey used a two-stage sampling design method to select a nationally-representative sample of 12,831 households. The first stage involved sampling 427 clusters from the updated frame used for the 2010 Ghana Population Census. This is made up of 216 urban clusters as well as 211 clusters from rural areas. Thirty households were then selected, in the second stage using a systematic sampling method

This study uses information from the Child Recode of the 2014 GDHS, which contains data on children born in the five years (2009-2014) preceding the survey to the interviewed women. It contains the information related to the child's pregnancy and postnatal care and immunization and health. It also provides information on the mother's health, education and other characteristics as well as father's background characteristics (GSS, 2015).

This period allows us to estimate the impact of the second phase of the free maternal health care program on family planning decisions as well as maternal and child health outcomes with the assumption that, the length of the period allows agents to have adequate information, based on which they make their reproductive health decisions.

\section{Methodology}




\section{a. Maternal Healthcare Access}

We estimate four different models for evidence of the impact of the FMHCP on all stages along the pregnancy-birth continuum; antenatal care, type of assistance at delivery and post-natal baby check-ups. Mathematically, these can be represented as follows;

$\operatorname{Logit}_{\left(\text {Nurse }_{i}\right)}=\ln \left(\frac{N}{1-N}\right)=\alpha+\beta \boldsymbol{F} \boldsymbol{M} \boldsymbol{H}_{\boldsymbol{i}}+\sigma^{\prime} \boldsymbol{X}_{i}+\varepsilon_{i} \ldots$
Logit $\left(T B A_{i}\right)=\ln \left(\frac{T}{1-T}\right)=\alpha+\beta \boldsymbol{F} \boldsymbol{M} \boldsymbol{H}_{i}+\sigma^{\prime} \boldsymbol{X}_{i}+\varepsilon_{i} \ldots$ (2)

$A N C_{i}=\alpha+\beta F M H_{i}+\sigma^{\prime} \boldsymbol{X}_{i}+\varepsilon_{i} \ldots$

Logit $\left(P N C_{i}\right)=\ln \left(\frac{P}{1-P}\right)=\alpha+\beta \boldsymbol{F} \boldsymbol{M} \boldsymbol{H}_{\boldsymbol{i}}+\sigma^{\prime} \boldsymbol{X}_{i}+\varepsilon_{i} \ldots$ (4)

Where, Nurse represents the probability that a woman in household $i$, used a skilled birth attendant at delivery. $F M H I$, on the other hand is a dummy for woman who has enrolled in the FMCHP whilst $\boldsymbol{X}$ is a vector of household level covariates that may potentially affect our outcome variable. In equation (2), we estimate a similar model in equation (1) for the probability that a woman used a traditional birth attendant, during delivery, where TBA is a dummy for using a traditional birth attendant at delivery. Equation (3) is an OLS estimation of how the FMHI impacts the number of antenatal care visits a woman makes during pregnancy whilst equation (4) is a logistic modelling of the effect of the FMHCP on post-natal health care. The variable ANC thus is a continuous variable that measures the number of antenatal care visits, a woman made during the reported pregnancy whilst PNC measures whether the baby received any post-natal checks within two months of delivery. Finally $\alpha$ is the constant term whilst $\varepsilon_{i}$ is the random error term. With the exception of the outcome variables, all other covariates enter the remaining equations, from equation (1).

Our choice of outcome variables for measuring access to maternal health care is informed by the empirical health literature. The literature recognizes labour and delivery as the most critical period of the maternal life, as most maternal deaths occur as a result of delivery-related complications. In view of this, the proportion of deliveries by a skilled attendant is used as a proxy for measuring maternal healthcare progress (WHO, 2015; GSS 2014). 
Our main explanatory variable is $F M H$, a dummy for a woman who is enrolled on the National Health Insurance Scheme, a close proxy for the free maternal health care program. The variable assigns a value of 1 to women who are covered by the National Health Insurance Scheme. Approximately, $74 \%$ of the women surveyed reported having subscribed to the NHIS. The other explanatory variables that enter our estimations are both categorical and continuous. We provide a brief overview of the variables that enter our regressions. Recognizing that poverty presents a significant barrier to health care access, even in the absence of user-fees. The inability of the poor to fully cover non-facility costs may well inhibit the full realization of the policy of objectives of the FMHI (Mayhew et al., 2008; Witter et al., 2009). To control for the effect of income and poverty on access to maternal health care, we include both the poor household and rich household dummies. These dummies represent the probabilities that the household belong to the lowest wealth quintile (poor) or the fourth wealth quintile among the surveyed households.

There also exists ample evidence on the role of education on maternal health outcomes. Education provides women with the ability to appreciate health information and utilize them to improve both their own health and of their children. It is therefore common for models that estimate determinants of maternal and child health outcomes to include controls for both maternal education and non-education. Raghupathy (1996) for example, argues based on evidence from Thailand, that secondary education is the most consistent predictor of health service use. Consistent with the literature, we include dummies for the woman's secondary education and non-formal education. However, the effects of the woman's own education on her own maternal health and that of the child may be over-estimated if the spouse's education is not controlled for. Generally, having an educated spouse is associated with a higher likelihood of making optimal health choices and producing and raising healthy children (Nuhu, 2016). Thomas (1994) finds similar evidence from Ghana, Brazil and the United States. To control for the unobserved impacts of spouse's education on maternal health choices, we include to dummies that capture both an uneducated husband and a husband who has received secondary education. Consistent with the literature, other variables that enter our estimations include the woman's 
own age and her spouse's age. In Table 1.0, we provide the descriptive statistics of the variables used in our estimations.

\section{b. Family Planning}

Family planning as a tool for population growth management, remains an important policy objective of the government of Ghana as highlighted in several policy documents. Family planning programs have generally sought to provide information, education, and counselling to individuals and couples on responsible child bearing and spacing, the and the use of contraceptives and other safe methods to reduce sexually transmitted infections including HIV and AIDS (MOH, 2011; GSS, 2015 and GHS 2014). However, inadequate funding for the family planning programme has affected progress towards the set goals. In response, the government of Ghana has passed a law to include family planning in the National Health Insurance Scheme (GSS, 2015) which is also free for pregnant women. To test the impact of the free maternal healthcare program on family planning, we examine the impact of the program on two measures of family planning; intention to use contraceptives/other family planning methods and the ideal number of children a couple desires to have. Mathematically, these are represented below;

Logit $\left(F P_{i}\right)=\ln \left(\frac{F P}{1-F P}\right)=\alpha+\beta F M H_{i}+x_{j}^{\prime} \boldsymbol{B}_{i}+\varepsilon_{i} \ldots$ (4)

$\operatorname{Kids}_{i}=\alpha+\beta F M H_{i}+x_{j}^{\prime} \boldsymbol{B}_{i}+\varepsilon_{i}$

Equation (4) represents a logistic estimation of the impact of the free maternal healthcare policy on the couple's intention to use family planning in the future. The outcome variable, $F P$, is a binary variable that assigns a value of 1 to a couple that does not intend to use family planning in the future. $F M H$ is a dummy for a woman who is enrolled in the free maternal health care program whilst $\boldsymbol{B}_{i}$ is a vector of covariates that affect the outcome variable. Equation (5) employs the ordinary least squares strategy to estimate the impact of the program or ideal number of children a couple wishes to have. Accordingly, the variable $K i d s_{i}$, is a continuous variable that 
measures the number of children a couple desires to have. Finally, $\alpha$ is the constant term whilst $\varepsilon_{i}$ is the random error term.

The vector of explanatory covariates that enter the first equation are motivated by the family planning hypothesis (Schultz, 1969). This model explains family planning as a function, of family size goal (the number of surviving a family wishes to have), past incidence of death of offspring, which tends to necessitate the adjustment of birth rates to achieve the desired family size goal, and uncertainty in the family formation process (Schultz, 1969). Typically, for both rich and poor households, children may be seen as consumption goods as they provide satisfaction and are usually a mark of social pride. However, whilst childbearing by poor families may be limited by income, it may also be a deliberate means to increase the family's labour supply; production goods. This incentive to see children as production good may be higher for poor households (Becker, 1960; Schultz, 1969) and thus economic theory generally considers higher fertility as a rational response to poverty. On the basis of the foregoing, we include the poor and rich household dummies, educational characteristics of the woman and her spouse as well as their ages as determinants of the family size goal.

Additionally, we control for the separate effects of the number of sons and daughter who have died in the past, on the family's desire to have more children. Again to isolate the impact of exposure to family planning information, we include a dummy that captures whether the couple has recently received education on family planning. We also recognize the potential of religious beliefs to influence contraceptive use and family planning and family size goals. Accordingly, we include a dummy that measures whether the woman's religion prohibits the use of family planning. Finally, we include household population as a proxy for existing family size. We expect that, ceteris paribus, in keeping with norms and traditions of the Ghanaian society, households with smaller populations will desire bigger family sizes. The descriptive statistics of the data used for these estimations are provided in Table 2.0

\section{c. Child Survival}

We estimated an augmented version of the Mosley and Chen (1984) child survival model for developing countries to test the impact of the Free Maternal healthcare program on child survival 
probability. Mosley and Chen (1984) provides a framework that incorporates both socioeconomic and biological factors as determinants of child survival probability. Guided by this theory, we estimate the binomial logistic regression below

Logit $\left(S_{i}\right)=\ln \left(\frac{S}{1-S}\right)=\alpha+\lambda F M H_{i}+x_{j}^{\prime} \boldsymbol{B}_{i}+\varepsilon_{i} \ldots(6)$, where the variable $S$, is a dichotomous variable that assigns the value 1 , if a child born in the five years preceding the survey is alive. The variable, $F M H_{i}$ is a dummy for the woman enrolled in the free maternal healthcare program, $\alpha$ is the constant term, $\boldsymbol{B}_{i}$ is a vector of socioeconomic and biological covariates that could affect child survival whilst $\varepsilon_{i}$ is the random error term. Specifically, we include the woman's Body Mass Index, as a proxy for the woman's own health status, an important determinant of child health and survival (Nuhu, 2016). Recognizing that maternity protection for working women is essential to their health and well-being and to that of their children, we include a dummy for whether the woman took maternity leave after the last birth, as mandated by law (GSS, 2015). Finally, we control for the unobserved effects of regional differences and urban and rural residency disparities in healthcare facilities, as well as non-facility costs, by including regional and residency dummies in all regressions. Mathematically, the marginal effects of the estimated models are computed from the general model:

$$
\operatorname{Pr}(Y=1 \mid F M H, \boldsymbol{B})=p=\frac{\exp \left(\alpha+\beta F M H_{i}+x_{j}^{\prime} \boldsymbol{B}_{i}\right)}{\exp \left(1+\alpha+\beta F M H_{i}+x_{j}^{\prime} \boldsymbol{B}_{i}\right)}
$$

By taking the partial derivative of $\mathrm{Y}$, with respect to $\mathrm{FMH}$, we obtain, the marginal effect of $a$ switch in the explanatory variable FMH on the probability of a change in the outcome variable of interest, $Y$.

$$
\frac{\partial \operatorname{Pr}(Y=1 \mid F M H, \boldsymbol{B})}{\partial F M H_{i}}=\frac{d Y(x B)}{d F M H} * \boldsymbol{B}
$$

\section{Results and Discussions}

The summary of our findings are reported in Tables3- Table 8 of the Appendix (Pg. 20-27). We first report the OLS estimates (for the linear models) and the marginal effects (for the logit models) without controlling for regional fixed effects. As robustness check, we re-estimate all the structural models by including the regional fixed effects. For the linear models, the estimated parameters represent the effect of a unit change (in the case of a continuous variable) or switch 
(in a dummy variable) on the outcome variable, holding other factors constant. The marginal effects in the logit estimations on the other hand, represent the effect of a switch or change in the explanatory variable on the probability of change in our outcome variable of interest. Since the log-pseudo R-Squared is of little relevance in explaining the goodness of fit, it is not reported. However, the more useful Likelihood Ratio (LR) Chi Square statistics which measure the joint significance of the model are reported with their corresponding probabilities.

\section{Effects on Maternal Health-Seeking Behavior}

As shown in Table 3.0, we find that enrollment in the Free Maternal Health Care programme (health insurance) increases the probability of utilizing skilled delivery assistance by about $8 \%$. This increases to about $9 \%$ after controlling for regional differences and remains highly significant below the $1 \%$ level. Again, we find that households in the second and third quintiles of income are more likely to use skilled delivery assistance relative to poor households. Also a woman with either primary, secondary or tertiary education is found to be more likely to use skilled assistance at birth delivery relative to a woman with no education. For those with primary education, it increases the probability by about $12 \%$ whilst having secondary or tertiary education increases the probability about $20 \%$ in both cases. These findings remain consistent and significant below the $1 \%$ level even after controlling for regional differences. Even though husband's education has similar effects and it is significant below $5 \%$, across secondary and tertiary levels, we find a woman whose husband has only primary education less likely to use skilled birth assistance. Again, whilst the woman's age was not significant, an additional year of the husband decreases the likelihood of using skilled birth assistance by about $0.2 \%$ and it is significant at the $5 \%$ level. Being married or living in an urban area is also found to increase the probability of using skilled birth attendance and is highly significant.

Conversely, we find that being enrolled in the programme significantly reduces the probability of using unskilled traditional birth assistance relative to other methods, by about $4 \%$ and it is consistent even after controlling for regional differences. Women in households within the first three income quintiles are also found to be less likely to use unskilled traditional birth attendant. Urban residency, and educational attainments on the part of both the woman and her husband's 
reduces the probability of using traditional delivery assistance as well. Again, even though both the woman and husband's age are not significant, we find married couples to be less likely to use unskilled birth attendant, at delivery. These findings are consistent across specifications

On antenatal care, we find that the number of times a woman goes for antenatal care increases by 0.6 times, if she is enrolled in the program, holding other factors constant. Income, however seems to have a more dominant effect. Specifically, belonging to the first or second quintile of income increases the frequency of antenatal care visits by about 1.7 or 1.4 times respectively. These remain significant below the $1 \%$ level even after controlling for regional differences. All levels of education for the woman are found to be positively and significantly related to the frequency of antenatal care visits, relative to a woman with no education at all. Additionally, having a husband with secondary education also significantly increases the number of times the woman goes for antenatal care, by 0.5 times. Again, even though being married was positively related to the frequency of antenatal care, it becomes insignificant after controlling for regional differences. We also find the wife's age to be significant and positively related to the frequency of antenatal care visits and this is consistent after controlling for regional fixed effects.

On Postnatal Care, we find that enrollment in the programme significantly increases the probability of going for postnatal care within the first three months of birth, by about $6 \%$ and it is significant at the $1 \%$ level, even after controlling for regional differences. Interestingly we find the probability of going for postnatal care women to be about $7 \%$ less likely for women in the middle income quintile relative to poorer households. Even though only primary education of the woman was not significant in determining whether a woman would go for postnatal care, other levels of education become significant after we control for regional differences. Again, both woman's age and husband's age did not matter for whether the woman received postnatal care, but being in an urban area is found to be positively and significantly related to the probability that a woman would go for postnatal care within the first three months of birth.

\section{Effects on Child Survival}

The findings of our augmented Chen and Mosely Child Survival model are reported in Table 5 on page 25 , with the fixed effects in Table 8.0 on page 27 . This model presents interesting 
findings; the only variable that is significant is whether the insurance covers the child. This increases the probability of child survival by about $2.5 \%$ and it is significant below the $5 \%$ level even after controlling for regional fixed effects. Mother's body mass index; a proxy for the mother's health and whether the woman took maternity leave during the pregnancy was also not significant. However, LR Chi Square statistic suggests that the estimated model is jointly significant below the $5 \%$ significance level.

\section{Family Planning}

We estimate the impact of the programme on two measures of family planning; the intention to use family planning (by using contraceptives or other methods) and the ideal number of children desired by the woman. Our findings are summarized in Tables 4.0 and 7.0 (pg. 23 \& 27). On the intention to use family planning, we find that being enrolled in the programme increases the probability of intending to use contraceptives by about $10 \%$ and it is significant at the $1 \%$ level. However, we find that high income families are less likely to use contraceptives relative to low income families even though this becomes insignificant after controlling for regional fixed effects. Again, the older the woman, the less likely she is to use contraceptives. We also find that, women in urban areas are also about $12 \%$ less likely to use contraceptives as compared to those in rural areas. And it is significant below the $1 \%$ level even after controlling for regional fixed effects. Another significant factor that explains the intention to use contraceptives, is religious prohibition. Women who reported that, their religious beliefs prohibited them from using contraceptives are found to be about $50 \%$ less likely to use contraceptives. Again, even though hearing about family planning on radio had a positive impact on the intention to use family planning, it becomes insignificant after we control for the regional fixed effects. Again we find all levels of husband's education to be positively related to the intention to use contraceptives, only secondary education is significant but it also becomes insignificant after we control for the regional differences.

On the ideal number of children the woman desires to have, we find that being enrolled in the programme was not a significant determinant, even after controlling for the regional fixed effects. However we find that belonging to the first income quintile reduces the desired number 
of children by about 0.6 children. Belonging to the second and third income quintile families have similar effects and it is also significant below the $1 \%$ level. Similarly, the number of children desired by women with only primary education is lower by 0.2 children, relative to others. However, amongst women with higher education, the desired number of children is lower by 0.8 relative to women without higher education and is highly significant. Husband education shows similar effects across all specifications. Again, even though the number of male and female children who have died8in the past was not significant, the number of dead female children is found to significantly increase the number of desired children, after controlling for the regional fixed effects. A one year increase in a woman's age also increases the number of desired children by about 0.04 children and it is also highly significant.

\section{Conclusion and Recommendation}

This paper sought to answer a simple question; what happens to maternal health seekingbehavior when health user-fees are removed? We analyze this question empirically by investigating the effects of the free maternal health care (Health Insurance) policy instituted by the government of Ghana, on a variety of health utilization measures and child survival outcomes. Using robust linear and binomial logistic estimation techniques, we find evidence from over 4,000 households, that enrolling on the free maternal health care programme significantly increases utilization of skilled birth assistance whilst simultaneously reducing the number of deliveries assisted by unskilled birth attendants. Utilization of antenatal and postnatal care experience similar effects with user-fee elimination. Even though intention to use family planning increases with enrollment in the programme, the number of children a woman desires to have is not influenced by her subscription to the programme. We also find child survival chances to be positively and significantly related to enrolment in the programme.

This paper adds voice to the growing evidence in support of removal of user-fees across the developing world. However, whilst such insurance schemes may improve utilization and child survival outcomes, the evidence also shows there exists significant inequality in utilization across income groups; a challenge that requires policy attention. In view of this, we propose that government and institutions must adopt double-edged policies; aimed at both enhancing access 
and ensuring equity and utilization. With regards to family planning, our paper shows that an overemphasis on the use of contraceptives-as a means of controlling population growth may not be optimal relative to shaping the views of individuals regarding desired number of children. As can be seen, whilst formal education across all levels have an insignificant impact on intention to use contraceptives, it significantly reduces the number of children a couple desires to have. In view of this we recommend that family planning education, not only focus on the use of contraceptives but also or perhaps mainly, on the number of children families wish to have. 


\section{References}

Akashi, H., Yamada, T., Huot, E., Kanal, K., \& Sugimoto, T. (2004). User fees at a public hospital in Cambodia: effects on hospital performance and provider attitudes. Social science \& medicine, 58(3), 553-564.

Audibert, M., \& Mathonnat, J. (2000). Cost recovery in Mauritania: initial lessons. Health Policy and Planning, 15(1), 66-75.

Barber, S., Bonnet, F., \& Bekedam, H. (2004). Formalizing under-the-table payments to control out-ofpocket hospital expenditures in Cambodia. Health Policy and Planning, 19(4), 199-208.

Bate, A., \& Witter, S. (2003). COPING WITH COMMUNITY HEALTH FINANCING: Illness costs and their implications for poor households' abilities to pay for health care and children's access to health services. A Study for Save the Children UK.

Becker, G. S. (1960). An economic analysis of fertility Demographic and economic change in developed countries (pp. 209-240): Columbia University Press.

Bitrán, R., \& Giedion, U. (2002). Waivers and exemptions for health services in developing countries. Final draft. World Bank, 89.

Borghi, J., Ensor, T., Somanathan, A., Lissner, C., Mills, A., \& group, L. M. S. S. s. (2006). Mobilising financial resources for maternal health. The lancet, 368(9545), 1457-1465.

Bosu, W., Bell, J., Armar-Klemesu, M., \& Tornui, J. (2007). Effect of delivery care user fee exemption policy on institutional maternal deaths in the Central and Volta Regions of Ghana. Ghana medical journal, 41(3).

Chawla, M., \& Ellis, R. P. (2000). The impact of financing and quality changes on health care demand in Niger. Health Policy and Planning, 15(1), 76-84.

Deininger, K., \& Mpuga, P. (2004). Economic and welfare effects of the abolition of health user fees: evidence from Uganda. World Bank policy research working paper(3276).

Diop, F., Yazbeck, A., \& Bitran, R. (1995). The impact of alternative cost recovery schemes on access and equity in Niger. Health Policy and Planning, 10(3), 223-240.

Dixon, J., Tenkorang, E. Y., Luginaah, I. N., Kuuire, V. Z., \& Boateng, G. O. (2014). National health insurance scheme enrolment and antenatal care among women in Ghana: is there any relationship? Tropical Medicine \& International Health, 19(1), 98-106.

Dzakpasu, S., Soremekun, S., Manu, A., ten Asbroek, G., Tawiah, C., Hurt, L., . . Campbell, O. M. (2012). Impact of free delivery care on health facility delivery and insurance coverage in Ghana's Brong Ahafo region. PloS one, 7(11), e49430.

Ellis, R. P. (1987). The revenue generating potential of user fees in Kenyan government health facilities. Social science \& medicine, 25(9), 995-1002.

Ensor, T., \& Cooper, S. (2004). Overcoming barriers to health service access: influencing the demand side. Health Policy and Planning, 19(2), 69-79.

Fabricant, S. J., Kamara, C. W., \& Mills, A. (1999). Why the poor pay more: household curative expenditures in rural Sierra Leone. The International journal of health planning and management, 14(3), 179199.

Ghana Statistical Service (GSS), Ghana Health Service (GHS), and ICF International (2015) Ghana

Demographic and Health Survey 2014. Rockville, Maryland, USA: GSS, GHS, and ICF International.

Ghana Health Service (2015), Improve Maternal Healthcare

http://www.ghanahealthservice.org/maternal-health.php, Retrieved on $15^{\text {th }}$ March 2016 
Ghana Health Service (2014), National Reproductive Health Service Policy and Standards, Third Edition. Accra, Ghana: GHS.

Haddad, S., \& Fournier, P. (1995). Quality, cost and utilization of health services in developing countries. A longitudinal study in Zaire. Social science \& medicine, 40(6), 743-753.

HERA and Health Partners Ghana (2013), Evaluation of the Free Maternal Health Care Initiative in Ghana, Retrieved from http://www.unicef.org/evaldatabase/index_70025.html

Jacobs, B., \& Price, N. (2004). The impact of the introduction of user fees at a district hospital in Cambodia. Health Policy and Planning, 19(5), 310-321.

James, C. D., Hanson, K., McPake, B., Balabanova, D., Gwatkin, D., Hopwood, I., . . Morris, S. S. (2006). To retain or remove user fees? Applied health economics and health policy, 5(3), 137-153.

Mariko, M. (2003). Quality of care and the demand for health services in Bamako, Mali: the specific roles of structural, process, and outcome components. Social science \& medicine, 56(6), 1183-1196.

Mayhew, M., Hansen, P. M., Peters, D. H., Edward, A., Singh, L. P., Dwivedi, V., . . Burnham, G. (2008). Determinants of skilled birth attendant utilization in Afghanistan: a cross-sectional study. American journal of public health, 98(10), 1849-1856.

McIntyre, D., Thiede, M., Dahlgren, G., \& Whitehead, M. (2006). What are the economic consequences for households of illness and of paying for health care in low-and middle-income country contexts? Social science \& medicine, 62(4), 858-865.

Ministry of Health. Guidelines for implementing the exemption policy on maternal deliveries. Accra:

Ministry of Health; 2004. Report No.: MoH/Policy, Planning, Monitoring and Evaluation- 59

Ministry of Health (MoH) [Ghana] (2011, Reproductive Health Commodity Security Strategy (RHCS), 20112016. Accra, Ghana: MoH.

Mosley, W. H., \& Chen, L. C. (1984). An analytical framework for the study of child survival in developing countries. Population and development review, 10, 25-45.

Nuhu, A. S. (2016). Intrahousehold Bargaining, Domestic Violence Laws and Child Health Development in Ghana. Journal of Economic and Social Thought, 3(1), 126-138.

Nyonator, F., \& Kutzin, J. (1999). Health for some? The effects of user fees in the Volta Region of Ghana. Health Policy and Planning, 14(4), 329-341.

Raghupathy, S. (1996). Education and the use of maternal health care in Thailand. Social science \& medicine, 43(4), 459-471.

Russell, S., \& Abdella, K. (2002). Too poor to be sick: Coping with the costs of illness in East Hararghe, Ethiopia. London: Save the Children.

Schultz, T. P. (1969). An economic model of family planning and fertility. The journal of political economy, 153-180.

Soucat, A., Gandaho, T., Levy-Bruhl, D., de Bethune, X., Alihonou, E., Ortiz, C., . . Ndiaye, J. M. (1997). Health seeking behaviour and household health expenditures in Benin and Guinea: the equity implications of the Bamako Initiative. The International journal of health planning and management, 12(S1), S137-S163.

Thomas, D. (1994). Like father, like son; like mother, like daughter: Parental resources and child height. Journal of Human Resources, 950-988.

UNICEF, 1999 The Bamako Initiative, http://www.unicef.org/media/media_11991.html 
Uzochukwu, B., Onwujekwe, O., \& Eriksson, B. (2004). Inequity in the Bamako Initiative programme-implications for the treatment of malaria in south-east Nigeria. The International journal of health planning and management, 19(S1), S107-S116.

WHO, 2015 http://www.who.int/mediacentre/factsheets/fs348/en/

Witter, S. (2005). An Unnecessary Evil? User fees for healthcare in low-income countries.

Witter, S., Adjei, S., Armar-Klemesu, M., \& Graham, W. (2009). Providing free maternal health care: ten lessons from an evaluation of the national delivery exemption policy in Ghana. Global Health Action, 2.

Witter, S., Arhinful, D. K., Kusi, A., \& Zakariah-Akoto, S. (2007). The experience of Ghana in implementing a user fee exemption policy to provide free delivery care. Reproductive health matters, 15(30), 61-71.

Witter, S., Garshong, B., \& Ridde, V. (2013). An exploratory study of the policy process and early implementation of the free NHIS coverage for pregnant women in Ghana. Int J Equity Health, 12(16), 1-11. 


\begin{tabular}{|c|c|c|c|c|c|c|c|c|c|c|c|c|c|}
\hline \multicolumn{14}{|c|}{ Summary Statistics } \\
\hline \multirow{2}{*}{$\begin{array}{c}\text { Table } 1 \\
\text { Variable }\end{array}$} & \multicolumn{3}{|c|}{ Skilled Assistance Delivery } & \multicolumn{3}{|c|}{ Traditional Birth Attendant } & \multicolumn{3}{|c|}{ Received Post Natal Care } & \multicolumn{4}{|c|}{ Antenatal Care Visits >0 } \\
\hline & & Mean & Std. Dev & & Mean & Std. Dev & & Mean & Std. Dev & Mean & Std. Dev & Min & Max \\
\hline Has Health Insurance & & 0.79 & 0.41 & & 0.67 & 0.47 & & 0.77 & 0.42 & 0.77 & 0.42 & 0 & 1 \\
\hline \multicolumn{14}{|l|}{ Wealth Quintile } \\
\hline Lowest-Poor & & 0.22 & 0.42 & & 0.53 & 0.50 & & 0.32 & 0.47 & 0.32 & 0.47 & 0 & 1 \\
\hline Fourth-Rich & & 0.20 & 0.40 & & 0.03 & 0.18 & & 0.16 & 0.37 & 0.16 & 0.37 & 0 & 1 \\
\hline \multicolumn{14}{|l|}{ Woman's X'tics } \\
\hline No Education & & 0.24 & 0.43 & & 0.57 & 0.50 & & 0.34 & 0.47 & 0.34 & 0.47 & 0 & 1 \\
\hline Secondary Education & & 0.50 & 0.50 & & 0.22 & 0.41 & & 0.42 & 0.49 & 0.42 & 0.49 & 0 & 1 \\
\hline Age & & 30.23 & 6.72 & & 30.77 & 7.15 & & 30.76 & 7.07 & 30.76 & 7.07 & 15 & 49 \\
\hline Urban Residence & & 0.50 & 0.50 & & 0.15 & 0.36 & & 0.43 & 0.49 & 0.43 & 0.49 & 0 & 1 \\
\hline \multicolumn{14}{|l|}{ Region } \\
\hline Western & & 0.11 & 0.31 & & 0.07 & 0.25 & & 0.09 & 0.29 & 0.10 & 0.30 & 0 & 1 \\
\hline Central & & 0.11 & 0.31 & & 0.11 & 0.31 & & 0.10 & 0.31 & 0.10 & 0.30 & 0 & 1 \\
\hline Greater Accra & & 0.09 & 0.29 & & 0.03 & 0.16 & & 0.09 & 0.29 & 0.08 & 0.27 & 0 & 1 \\
\hline Volta & & 0.07 & 0.26 & & 0.07 & 0.26 & & 0.09 & 0.29 & 0.08 & 0.27 & 0 & 1 \\
\hline Eastern & & 0.09 & 0.29 & & 0.10 & 0.29 & & 0.04 & 0.20 & 0.09 & 0.29 & 0 & 1 \\
\hline Ashanti & & 0.12 & 0.33 & & 0.04 & 0.20 & & 0.10 & 0.29 & 0.10 & 0.30 & 0 & 1 \\
\hline Brong Ahafo & & 0.13 & 0.34 & & 0.08 & 0.27 & & 0.09 & 0.28 & 0.11 & 0.31 & 0 & 1 \\
\hline Northern & & 0.08 & 0.28 & & 0.34 & 0.47 & & 0.17 & 0.37 & 0.15 & 0.36 & 0 & 1 \\
\hline Upper East & & 0.12 & 0.33 & & 0.04 & 0.19 & & 0.13 & 0.34 & 0.09 & 0.29 & 0 & 1 \\
\hline Upper West & & 0.06 & 0.24 & & 0.13 & 0.34 & & 0.10 & 0.29 & 0.09 & 0.28 & 0 & 1 \\
\hline Sample Size & 3569 & & & 1093 & & & 3110 & & & & & & \\
\hline \multicolumn{14}{|l|}{ Husband X'tics } \\
\hline No Education & 3270 & 0.21 & 0.41 & 1046 & 0.53 & 0.50 & 2860 & 0.32 & 0.46 & 0.32 & 0.46 & 0 & 1 \\
\hline Sec. Education & 3270 & 0.43 & 0.49 & 1046 & 0.27 & 0.44 & 2860 & 0.36 & 0.48 & 0.36 & 0.48 & 0 & 1 \\
\hline Age & 3030 & 37.49 & 8.58 & 985 & 39.13 & 10.76 & 2639 & 38.47 & 9.65 & 38.478 & 9.65 & 17 & 81 \\
\hline
\end{tabular}




\begin{tabular}{|c|c|c|c|c|c|c|c|c|c|c|c|}
\hline \multirow{2}{*}{$\begin{array}{l}\text { Table } 2.0 \text { Summary Statistics } \\
\text { Variable }\end{array}$} & \multicolumn{3}{|c|}{ No Intention- Family Planning } & \multicolumn{3}{|c|}{ Ideal Family Size > Current } & \multicolumn{5}{|c|}{ Child Survived } \\
\hline & $\begin{array}{r}\text { Samp } \\
\text { le }\end{array}$ & Mean & Std. Dev & Sample & Mean & Std. Dev & $\begin{array}{r}\text { Samp } \\
\text { le }\end{array}$ & Mean & Std. Dev & Min & Max \\
\hline Has Health Insurance & 1687 & 0.70 & 0.46 & 1698 & 0.72 & 0.45 & & 0.74 & 0.44 & 0 & 1 \\
\hline Lowest Wealth Quintile-Poor & & 0.32 & 0.47 & & 0.35 & 0.48 & & 0.32 & 0.47 & 0 & 1 \\
\hline Fourth Wealth Quintile-Rich & & 0.16 & 0.36 & & 0.14 & 0.35 & & 0.15 & 0.36 & 0 & 1 \\
\hline \multicolumn{12}{|l|}{ Woman's Characteristics } \\
\hline No Education & & 0.39 & 0.49 & & 0.41 & 0.49 & & 0.34 & 0.47 & 0 & 1 \\
\hline Secondary Education & & 0.40 & 0.49 & & 0.35 & 0.48 & & 0.41 & 0.49 & 0 & 1 \\
\hline Age & & 31.98 & 7.09 & & 30.03 & 6.97 & & 30.56 & 6.88 & 15 & 47 \\
\hline Married & & 0.66 & 0.47 & & 0.63 & 0.48 & & 0.66 & 0.47 & 0 & 1 \\
\hline Body Mass Index & 840 & 24.26 & 4.99 & 869 & 24.06 & 4.57 & & 24.34 & 4.79 & 13.34 & 54.35 \\
\hline Took Maternity Leave & 796 & 0.18 & 0.39 & 814 & 0.20 & 0.40 & 2625 & 0.20 & 0.40 & 0 & 1 \\
\hline Religious Prohibits FamilyPlann & & 0.03 & 0.17 & & 0.02 & 0.13 & & 0.01 & 0.11 & 0 & 1 \\
\hline No. of Dead Sons & & 0.22 & 0.54 & & 0.23 & 0.54 & & 0.15 & 0.44 & 0 & 4 \\
\hline No. of Dead Daughters & & 0.18 & 0.44 & & 0.18 & 0.46 & & 0.12 & 0.36 & 0 & 3 \\
\hline Educated on FamilyPlann. & & 0.56 & 0.50 & & 0.51 & 0.50 & & 0.55 & 0.50 & 0 & 1 \\
\hline Urban Residence & 1687 & 0.48 & 0.50 & & 0.37 & 0.48 & 5595 & 0.40 & 0.49 & 0 & 1 \\
\hline Region & 1687 & & & & & & 5595 & & & & \\
\hline Western & & 0.09 & 0.29 & & 0.10 & 0.30 & & 0.10 & 0.30 & 0 & 1 \\
\hline Central & & 0.11 & 0.31 & & 0.08 & 0.27 & & 0.10 & 0.30 & 0 & 1 \\
\hline Greater Accra & & 0.10 & 0.30 & & 0.05 & 0.22 & & 0.08 & 0.27 & 0 & 1 \\
\hline Volta & & 0.06 & 0.24 & & 0.05 & 0.22 & & 0.08 & 0.27 & 0 & 1 \\
\hline Eastern & & 0.08 & 0.28 & & 0.09 & 0.29 & & 0.09 & 0.29 & 0 & 1 \\
\hline Ashanti & & 0.11 & 0.32 & & 0.10 & 0.30 & & 0.10 & 0.30 & 0 & 1 \\
\hline Brong Ahafo & & 0.10 & 0.30 & & 0.12 & 0.32 & & 0.11 & 0.32 & 0 & 1 \\
\hline Northern & & 0.21 & 0.41 & & 0.21 & 0.40 & & 0.15 & 0.36 & 0 & 1 \\
\hline Upper East & & 0.07 & 0.26 & & 0.10 & 0.30 & 5595 & 0.10 & 0.29 & 0 & 1 \\
\hline Upper West & & 0.05 & 0.21 & & 0.11 & 0.31 & 5595 & 0.08 & 0.28 & 0 & 1 \\
\hline (Husband) No Education & 1565 & 0.32 & 0.47 & 1599 & 0.38 & 0.48 & 5216 & 0.30 & 0.46 & 0 & 1 \\
\hline Secondary Education & 1565 & 0.37 & 0.48 & 1599 & 0.34 & 0.47 & 5216 & 0.38 & 0.49 & 0 & 1 \\
\hline Age & 1441 & 39.81 & 9.40 & 1448 & 36.91 & 9.75 & 4853 & 38.23 & 9.48 & 19 & 73 \\
\hline
\end{tabular}


Effects on Maternal Health-Seeking Behavior

\begin{tabular}{|c|c|c|c|c|}
\hline Marginal Effects & Skilled Assistance & Traditional Birth Attendant & ANC Frequency & Postnatal Care \\
\hline Health Insurance & $\begin{array}{c}0.075^{* * *} \\
(0.016)\end{array}$ & $\begin{array}{l}-0.040 \\
(0.010) \\
\end{array}$ & $\begin{array}{c}0.606 * * * \\
(0.097)\end{array}$ & $\begin{array}{c}0.059 * * * \\
(0.016)\end{array}$ \\
\hline Wealth Index Richest & $\begin{array}{c}0.029 \\
(0.035) \\
\end{array}$ & $\begin{array}{c}-0.255^{* * *} \\
(0.044)\end{array}$ & $\begin{array}{c}1.745^{* * *} \\
(0.190)\end{array}$ & $\begin{array}{c}0.006 \\
(0.034)\end{array}$ \\
\hline Wealth Index Rich & $\begin{array}{c}0.188^{* * *} \\
(0.029)\end{array}$ & $\begin{array}{c}-0.157^{* * *} \\
(0.024)\end{array}$ & $\begin{array}{c}1.433^{* * *} \\
(0.155)\end{array}$ & $\begin{array}{l}-0.026 \\
(0.027)\end{array}$ \\
\hline Wealth index Middle & $\begin{array}{c}0.094^{* * *} \\
(0.022)\end{array}$ & $\begin{array}{c}-0.042 * * \\
(0.015)\end{array}$ & $\begin{array}{c}0.679 * * * \\
(0.140)\end{array}$ & $\begin{array}{c}-0.070 * * * \\
(0.022)\end{array}$ \\
\hline $\begin{array}{c}\text { Woman's Education } \\
\text { Primary School }\end{array}$ & $\begin{array}{c}0.126 * * * \\
(0.021)\end{array}$ & $\begin{array}{c}-0.048^{* * *} \\
(0.013)\end{array}$ & $\begin{array}{c}0.515^{* * *} \\
(0.135)\end{array}$ & $\begin{array}{c}0.013 \\
(0.022) \\
\end{array}$ \\
\hline Secondary School & $\begin{array}{c}0.207^{* * * *} \\
(0.021)\end{array}$ & $\begin{array}{c}-0.080 * * * \\
(0.014)\end{array}$ & $\begin{array}{c}0.603^{* * *} \\
(0.129)\end{array}$ & $\begin{array}{c}0.011 \\
(0.022)\end{array}$ \\
\hline Higher Education & $\begin{array}{c}0.203^{* * *} \\
(0.054)\end{array}$ & . & $\begin{array}{c}0.996 * * * \\
(0.254)\end{array}$ & $\begin{array}{c}0.057 \\
(0.052)\end{array}$ \\
\hline $\begin{array}{l}\text { Husband's Education } \\
\text { Complete Primary }\end{array}$ & $\begin{array}{l}-0.075^{*} \\
(0.041)\end{array}$ & $\begin{array}{l}-0.003 \\
(0.024)\end{array}$ & $\begin{array}{c}0.227 \\
(0.265)\end{array}$ & $\begin{array}{c}-0.123 * * * \\
(0.039)\end{array}$ \\
\hline Incomplete Secondary & $\begin{array}{c}0.045^{* *} \\
(0.019)\end{array}$ & $\begin{array}{c}-0.054 * * * \\
(0.012)\end{array}$ & $\begin{array}{c}0.490 * * * \\
(0.124)\end{array}$ & $\begin{array}{c}-0.063 * * * \\
(0.020)\end{array}$ \\
\hline Complete Secondary & $\begin{array}{l}0.072 * * \\
(0.031)\end{array}$ & $\begin{array}{c}-0.053 * * \\
(0.023)\end{array}$ & $\begin{array}{c}0.541 * * * \\
(0.182)\end{array}$ & $\begin{array}{c}-0.032 \\
(0.030)\end{array}$ \\
\hline Higher Education & $\begin{array}{c}0.055 \\
(0.037)\end{array}$ & $\begin{array}{l}-0.051 \\
(0.032)\end{array}$ & $\begin{array}{c}0.266 \\
(0.187)\end{array}$ & $\begin{array}{l}-0.025 \\
(0.035)\end{array}$ \\
\hline Woman's Age & $\begin{array}{c}0.001 \\
(0.002)\end{array}$ & $\begin{array}{c}-0.001 \\
(0.001)\end{array}$ & $\begin{array}{c}0.025^{* * *} \\
(0.010)\end{array}$ & $\begin{array}{c}0.001 \\
(0.002)\end{array}$ \\
\hline Urban Residence & $\begin{array}{c}0.165 \\
(0.021)^{* * *}\end{array}$ & $\begin{array}{c}-0.086 * * * \\
(0.014)\end{array}$ & $\begin{array}{c}0.030 \\
(0.111)\end{array}$ & $\begin{array}{c}0.052^{* * *} \\
(0.020)\end{array}$ \\
\hline Married & $\begin{array}{c}0.064 * * * \\
(0.018)\end{array}$ & $\begin{array}{c}-0.031 * * \\
(0.012)\end{array}$ & $\begin{array}{c}0.283^{* *} \\
(0.115)\end{array}$ & $\begin{array}{c}0.075^{* * *} \\
(0.018)\end{array}$ \\
\hline Husband Age & $\begin{array}{c}-0.003 * * \\
(0.001)\end{array}$ & $\begin{array}{c}0.000 \\
(0.001)\end{array}$ & $\begin{array}{c}0.001 \\
(0.007)\end{array}$ & $\begin{array}{l}-0.002 \\
(0.001)\end{array}$ \\
\hline Sample Size & 5,091 & 4,891 & 3,600 & 3,606 \\
\hline Likelihood Ratio Chi Square/F-Stat & $782.75 * * *$ & $614.29 * * *$ & $41.87 * * *$ & $99.75 * * * *$ \\
\hline
\end{tabular}




\begin{tabular}{|c|c|c|c|c|}
\hline Table 4.0 & Effects on Family Planning Use and & red Numb & Children & \\
\hline Marginal Effects & $\begin{array}{l}\text { Intention to use Family Planning } \\
\text { (Binary) }\end{array}$ & P-Value & $\begin{array}{l}\text { Desired Number of Children } \\
\text { (Continuous) }\end{array}$ & P-Value \\
\hline Health Insurance & $\begin{array}{c}0.056^{* *} \\
(0.024)\end{array}$ & 0.019 & $\begin{array}{r}0.013 \\
10.090\end{array}$ & 0.890 \\
\hline Wealth Index Richest & $\begin{array}{c}-0.094 \\
(0.046) * *\end{array}$ & 0.044 & $\begin{array}{c}-0.650 * * * \\
(0.151)\end{array}$ & 0.000 \\
\hline Wealth Index Rich & $\begin{array}{l}-0.055 \\
(0.040)\end{array}$ & 0.170 & $\begin{array}{c}-0.660 * * * \\
(0.127)\end{array}$ & 0.000 \\
\hline Wealth index Middle & $\begin{array}{c}-0.061 \\
(0.032) *\end{array}$ & 0.058 & $\begin{array}{c}-0.360 * * * \\
(0.113)\end{array}$ & 0.002 \\
\hline $\begin{array}{l}\text { Woman's Education } \\
\text { Primary School }\end{array}$ & $\begin{array}{c}0.038 \\
(0.031)\end{array}$ & 0.217 & $\begin{array}{c}-0.531 * * * \\
(0.117)\end{array}$ & 0.000 \\
\hline Secondary School & $\begin{array}{l}-0.007 \\
(0.031)\end{array}$ & 0.826 & $\begin{array}{c}-0.974 * * * \\
(0.103)\end{array}$ & 0.000 \\
\hline Higher Education & $\begin{array}{c}0.031 \\
(0.071)\end{array}$ & 0.664 & $\begin{array}{c}-1.094^{* * *} \\
(0.199)\end{array}$ & 0.000 \\
\hline $\begin{array}{l}\text { Husband's Education } \\
\text { Complete Primary }\end{array}$ & $\begin{array}{c}0.099 \\
(0.061)\end{array}$ & 0.103 & $\begin{array}{c}-0.423^{* *} \\
(0.215)\end{array}$ & 0.050 \\
\hline Incomplete Secondary & $\begin{array}{c}0.015 \\
(0.029)\end{array}$ & 0.603 & $\begin{array}{c}-0.729 * * * \\
(0.100)\end{array}$ & 0.000 \\
\hline Complete Secondary & $\begin{array}{c}0.046 \\
(0.044)\end{array}$ & 0.296 & $\begin{array}{c}-0.644 * * * \\
(0.132) \\
\end{array}$ & 0.000 \\
\hline Higher Education & $\begin{array}{c}0.011 \\
(0.048)\end{array}$ & 0.814 & $\begin{array}{c}-0.792^{* * *} \\
(0.143)\end{array}$ & 0.000 \\
\hline Woman's Age & $\begin{array}{c}-0.012 * * * \\
(0.002)\end{array}$ & 0.000 & $\begin{array}{c}0.033^{* * *} * \\
(0.008)\end{array}$ & 0.000 \\
\hline Urban Residence & $\begin{array}{c}-0.116^{* * *} \\
(0.028)\end{array}$ & 0.000 & $\begin{array}{c}0.129 \\
(0.094) \\
\end{array}$ & 0.171 \\
\hline Married & $\begin{array}{c}0.023 \\
(0.025)\end{array}$ & 0.349 & $\begin{array}{c}0.057 \\
(0.093)\end{array}$ & 0.537 \\
\hline Husband Age & $\begin{array}{c}0.001 \\
(0.002)\end{array}$ & 0.572 & $\begin{array}{l}-0.002 \\
(0.006)\end{array}$ & 0.790 \\
\hline Religious Prohibition & $\begin{array}{c}-0.476 * * * \\
(0.107)\end{array}$ & 0.000 & $\begin{array}{l}0.698^{*} \\
(0.403) \\
\end{array}$ & 0.083 \\
\hline Number of Daughters Dead & -0.030 & 0.241 & $0.633^{* * *}$ & 0.000 \\
\hline
\end{tabular}




\begin{tabular}{|c|c|c|c|c|}
\hline & $(0.026)$ & & $(0.125)$ & \\
\hline Received Family Planning & $-0.037^{*}$ & 0.079 & 0.011 & 0.894 \\
\hline Education & $(0.021)$ & & $(0.079)$ & \\
\hline Number of Sons Dead & $\begin{array}{c}0.028 \\
(0.020)\end{array}$ & 0.164 & $\begin{array}{c}0.116 \\
(0.077)\end{array}$ & 0.129 \\
\hline Home Population & $\begin{array}{c}0.004 \\
(0.004)\end{array}$ & 0.278 & $\begin{array}{c}0.078 * * * \\
(0.016)\end{array}$ & 0.000 \\
\hline Sample & 2,427 & & 2,397 & \\
\hline Likelihood Ratio $\chi^{2}$ & $171.44 * * * *$ & & F-Statistic & $50.05 * * *$ \\
\hline
\end{tabular}

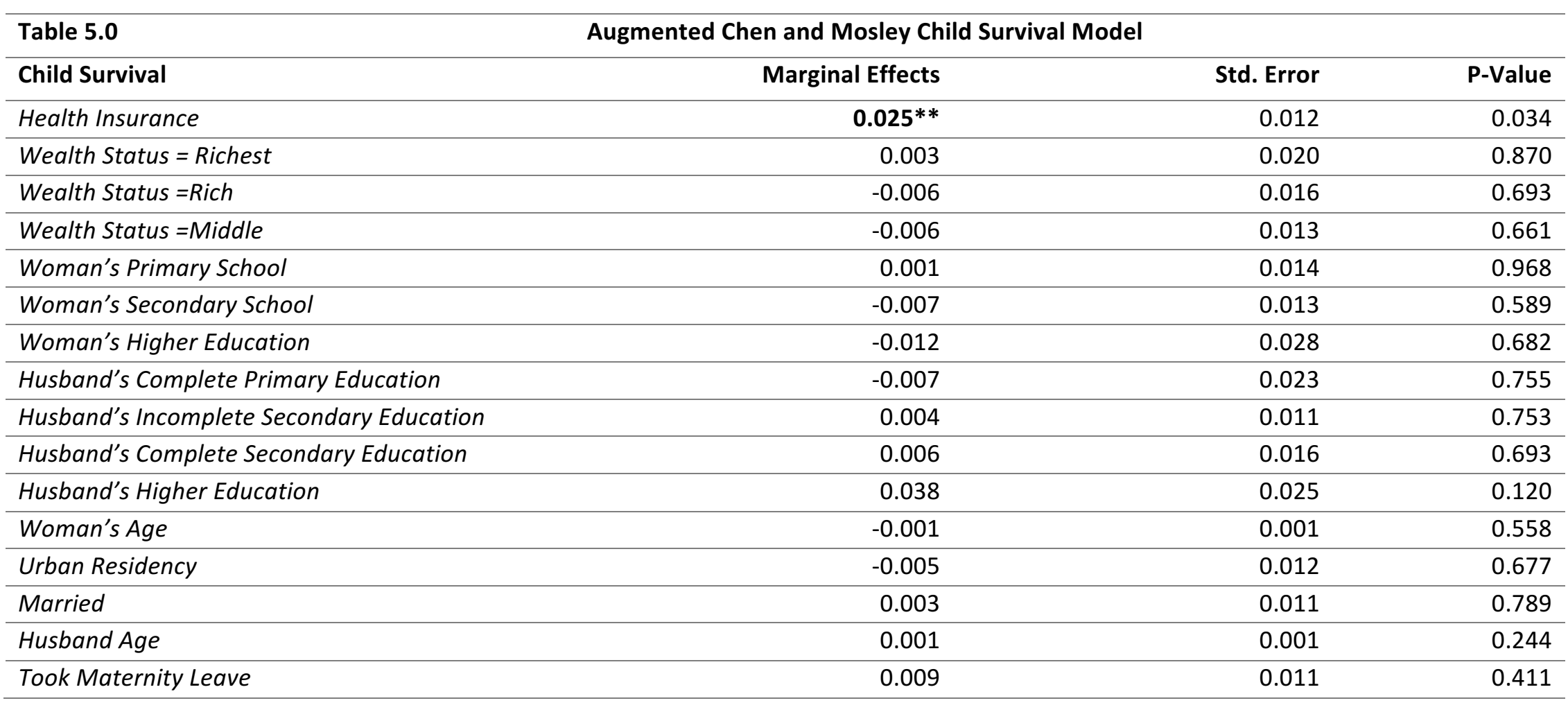




\begin{tabular}{lrr}
\hline Woman's Body Mass Index & $0.055^{* * *}$ & 0.001 \\
\hline Likelihood Ratio $\chi^{2}$ & $\mathbf{2 5 . 4 1 * * *} \quad$ Sample Size & $\mathbf{8 6 3}$ \\
\hline & $* * *$ Significant $<0.01 * *$ Significant $<0.05$ and *Significant $<0.10$
\end{tabular}

\begin{tabular}{|c|c|c|c|c|}
\hline \multirow[t]{2}{*}{ Table 6.0} & \multicolumn{3}{|c|}{ Maternal Health Seeking Model with Regional Fixed Effects } & \multirow[b]{2}{*}{ PNC } \\
\hline & Skilled Delivery & Traditional Delivery & ANC & \\
\hline \multirow[t]{2}{*}{ Health Insurance } & $0.086 * * *$ & $-0.040 * * *$ & $0.693 * * *$ & $0.042 * * *$ \\
\hline & $(0.017)$ & $(0.010)$ & $(0.099)$ & $(0.016)$ \\
\hline \multirow[t]{2}{*}{ Upper East } & $0.343^{* * *}$ & $-0.200 * * *$ & $0.827^{* * *}$ & $0.379 * * *$ \\
\hline & $(0.045)$ & $(0.038)$ & $(0.226)$ & $(0.055)$ \\
\hline \multirow[t]{2}{*}{ Upper West } & -0.069 & 0.013 & -0.195 & 0.094 \\
\hline & $(0.042)$ & $(0.033)$ & $(0.228)$ & $(0.042)^{* *}$ \\
\hline \multirow[t]{2}{*}{ Volta } & -0.087 & -0.025 & -0.468 & 0.066 \\
\hline & $(0.042)^{* *}$ & $(0.034)$ & $(0.254)^{* *}$ & $(0.042)$ \\
\hline \multirow[t]{2}{*}{ Northern } & -0.132 & $0.070 * *$ & -0.761 & $0.124^{* *}$ \\
\hline & $(0.040)^{* * *}$ & $(0.032)$ & $(0.230)^{* * *}$ & $(0.040)$ \\
\hline \multirow[t]{2}{*}{ Brong Ahafo } & $0.106^{* * *}$ & -0.044 & 0.477 & $-0.188 * * *$ \\
\hline & $(0.040)$ & $(0.033)$ & $(0.235)^{* *}$ & $(0.036)$ \\
\hline \multirow[t]{2}{*}{ Western } & 0.075 & -0.042 & $0.939 * * *$ & $-0.097 * * *$ \\
\hline & $(0.040)^{*}$ & $(0.034)$ & $(0.236)^{* * *}$ & $(0.036)$ \\
\hline \multirow[t]{2}{*}{ Central } & 0.006 & 0.035 & $0.603^{* *}$ & -0.020 \\
\hline & $(0.040)$ & $(0.032)$ & $(0.240)$ & $(0.037)$ \\
\hline \multirow[t]{2}{*}{ Eastern } & -0.014 & 0.017 & -0.699 & $-0.362 * * *$ \\
\hline & $(0.040)$ & $(0.033)$ & $(0.226)^{* * *}$ & $(0.037)$ \\
\hline \multirow[t]{2}{*}{ Ashanti } & 0.035 & -0.050 & $0.485^{* *}$ & $-0.092 * * *$ \\
\hline & $(0.039)$ & $(0.035)$ & $(0.224)$ & $(0.035)$ \\
\hline Sample & 5,091 & 4,891 & 3,600 & 3,606 \\
\hline Likelihood Ratio Chi Square/F-Stat & $847.41 * * *$ & $567.84 * * *$ & $38.23 * * *$ & $476.56 * * *$ \\
\hline Demographic Controls = Yes & & & & \\
\hline
\end{tabular}




\begin{tabular}{|c|c|c|}
\hline Table 7.0 & Family Planning Model with Regional & cts \\
\hline Marginal Effects & Intention to Use Family Planning & Ideal Family Size \\
\hline \multirow[t]{2}{*}{ Health Insurance } & 0.041 & 0.108 \\
\hline & $(0.025)$ & $(0.096)$ \\
\hline \multirow[t]{2}{*}{ Upper East } & $0.196 * * *$ & 0.148 \\
\hline & $(0.058)$ & $(0.185)$ \\
\hline \multirow[t]{2}{*}{ Upper West } & $0.233 * * *$ & 0.302 \\
\hline & $(0.060)$ & $(0.198)$ \\
\hline \multirow[t]{2}{*}{ Volta } & $0.179 * * *$ & -0.381 \\
\hline & $(0.058)$ & $(0.173)$ \\
\hline \multirow[t]{2}{*}{ Northern } & 0.024 & $1.329 * * *$ \\
\hline & $(0.053)$ & $(0.189)$ \\
\hline \multirow[t]{2}{*}{ Brong Ahafo } & $0.135 * *$ & -0.160 \\
\hline & $(0.055)$ & $(0.164)$ \\
\hline \multirow[t]{2}{*}{ Western } & 0.040 & $0.586 * * *$ \\
\hline & $(0.053)$ & $(0.179)$ \\
\hline \multirow[t]{2}{*}{ Central } & 0.018 & $-0.295 * *$ \\
\hline & $(0.052)$ & $(0.163)$ \\
\hline \multirow[t]{2}{*}{ Eastern } & $0.133^{* *}$ & -0.099 \\
\hline & $(0.054)$ & $(0.163)$ \\
\hline \multirow[t]{2}{*}{ Ashanti } & 0.066 & 0.079 \\
\hline & $(0.051)$ & $(0.158)$ \\
\hline Sample Size & 2,427 & 2,397 \\
\hline Demographic Controls = Yes & Likelihood Ratio $\chi^{2}$ 223.26*** & F-Statistic \\
\hline
\end{tabular}




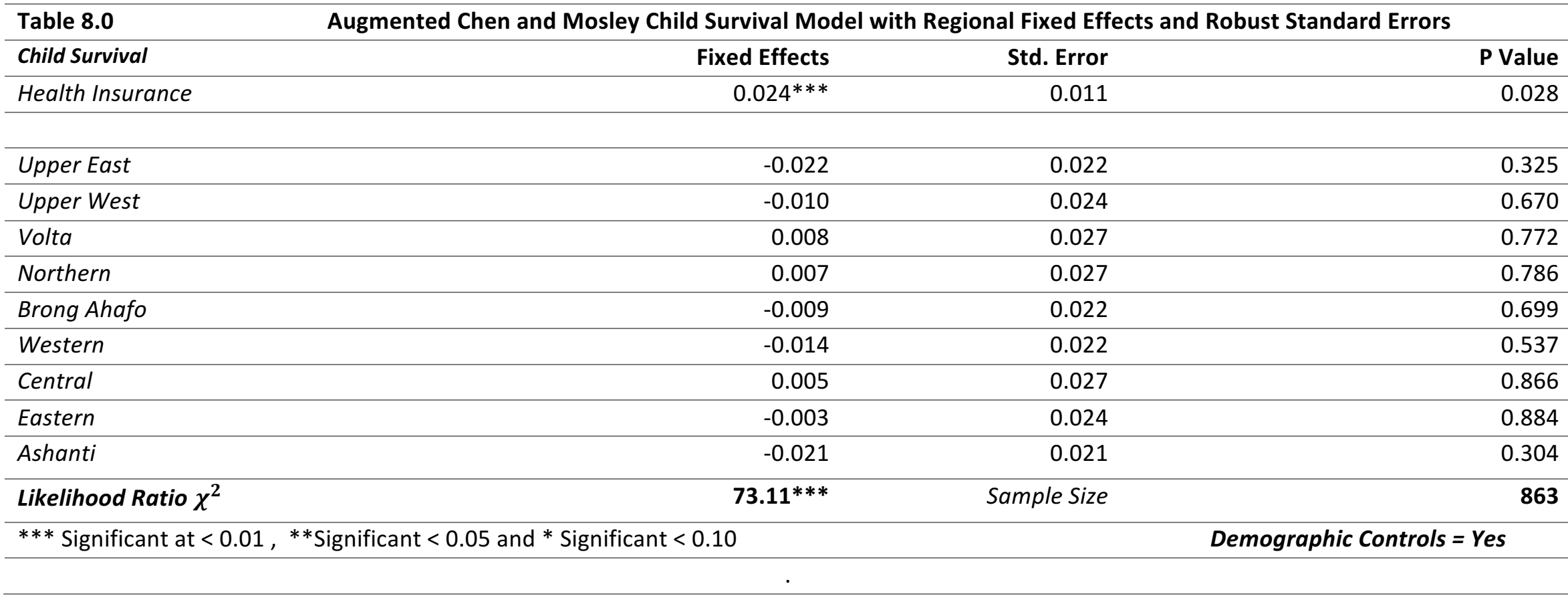

